\title{
Evaluation of Crop Residue Potential for Power Generation for Indian State Punjab
}

\author{
Jaswinder Singh $^{\mathrm{a}}$, Lakhwinder Singh $^{\mathrm{b}}$, Gurpreet Singh $^{\mathrm{c}}$ \\ ${ }^{a}$ Research Scholar University College of Engineering, Punjabi University Patiala, Patiala \\ ${ }^{b}$ Assistant Professor, Mechanical Engineering Department, College of Engineering \& Management, Rampura \\ Phul \\ ${ }^{c}$ Assistant Professor, Mechanical Engineering Department, University College of Engineering, Punjabi \\ University Patiala, Patiala
}

\begin{abstract}
The problem of disposal of agro residue in the beneficial way along with the problem of agro residue pollution is very serious problem of Indian state Punjab, so to address the problem along with the alternative methods of its disposal has been considered in this research paper. It has been investigated that around 14462.85 Thousand Ton year ${ }^{-1}$ is generated from various crops and it is further investigated that $917.57 \mathrm{MW}$ power can be generated through crop residue. Categorisation of crop residue has been done to further investigate the problem practically. It is found that in districts Gurdaspur, Amritsar, Tarn Taran, Kapurthala, Jalandhar, SBS Nagar, Hoshiarpur, Rupnagar, SAS Nagar, Ludhiana, Firozpur, Faridkot, Shri Muktsar Sahib, Moga, Bathinda, Mansa, Sangrur, Barnala, Patiala and Fatehgarh Sahib has energy potential approximately 59.55 MW, 40.96 MW, 41.26 MW, 34.99 MW, 50 MW, 25.36 MW, 53.93 MW, 20.44 MW, $13.43 \mathrm{MW}, 85.50$ $M W, 85.58 \mathrm{MW}, 31.72 \mathrm{MW}, 39.55 \mathrm{MW}, 42.43 \mathrm{MW}, 42.58 \mathrm{MW}, 30.74 \mathrm{MW}, 90.37 \mathrm{MW}, 35.36 \mathrm{MW}, 67.54 \mathrm{MW}$ and $26.28 \mathrm{MW}$ respectively.

Agricultural residues are spatially scattered in Punjab. The spatial distribution and associated costs on collection and transportation of this resource are the critical factor in planning the biomass based power plants. In this paper geographical information system is used to evaluate the feasibility of setting up biomass based power plants and optimizing their location. The Ultimate and Proximate analysis of crop residue has been done. In the present study, a downdraft biomass gasifier is used to carry out the gasification experiments with the cotton stalks as biomass fuel. Approximately $80 \%$ of diesel has been saved in the dual fuel mode of the gasification system.
\end{abstract}

\section{Introduction}

Historically, biomass has been a major source of household energy in India [1]. It meets the cooking energy needs of most rural households and half of the urban households [2]. The availability of affordable energy supply is an important component in improving the quality of life, but there is huge scarcity of energy supply in all the sectors of rural as well as urban economy of the country [3]. The trend on energy shows that the consumption rate of biomass energy is considerably on the rise, especially during the last couple of decades [4]. This is mainly because of increasing demand in both rural and urban areas and shortage of alternative fuels, thus the most important and viable option is extraction of energy from biomass resources.

In India the estimated electricity consumption increased from 43,724 GWh during 1970-71 to 6,94,392 GWh during $2010-11$. The increase in electricity consumption is $13.34 \%$ from $2009-10(6,12,645 \mathrm{GWh})$ to 2010-11(6, 94,392 GWh). Of the total electricity sales in 2010-11, industry sector accounted for the largest share $(38.6 \%)$, followed by domestic $(23.8 \%)$, agriculture (19.6\%) and commercial sector $(9.89 \%)$. However, it is seen that electricity consumption in domestic sector and agriculture sector has increased at a much faster pace compared to other sectors during $1970-71$ to $2010-11$, with $9.67 \%$ and $8.61 \%$ respectively [1]. It is estimated that India generates over $370 \mathrm{Mt}$ of biomass every year, but unfortunately at present this biomass resource is used inefficiently [5]. The present article draws from this study, focusing on the availability of surplus agricultural residue and its potential for power generation in Punjab, which is one of the agriculture rich states of India.

\subsection{Profile of Punjab state}

Punjab as of 2011 has a total population of 27.7 million, which is $2.29 \%$ of India's population. Of this, $62.51 \%$ live in rural areas [7]. The population density is high at 550 persons $/ \mathrm{sq} \mathrm{km}$ as compared to the national average of 327 persons/sq km. The sex ratio in Punjab has improved from 798 in 2001 to 893 in 2011. The child sex ratio in the age group 0-6 years has also improved from 798 in 2001 to 846 in 2011.

Punjab is a small state with 50362 sq. km geographical area. The land is primarily formed of the alluvium deposited by rivers of Indus system. About $83 \%$ of the total land is under agricultural activities 
including plantation, as compared to national average of $40.38 \%$. The recorded forest area in the state is 3058 $\mathrm{km}^{2}$ which is $6.12 \%$ of the total geographical area of the state.

Agriculture in Punjab is highly intensive in terms of agriculture inputs, such as, water, energy, nutrients, machinery, including the land value and capital invested. The state has $84 \%$ of its total geographical area (50.362 lakh hectares) under cultivation. The cropping intensity is around $189 \%$ with over $98 \%$ of the cultivable area being under assured irrigation. Fertilizer consumption at $235 \mathrm{~kg} / \mathrm{ha}$ is almost 1.84 times higher than the national average of $128 \mathrm{~kg} / \mathrm{ha}$. The State's farm economy is highly mechanized. $18 \%$ of the country's tractors are in Punjab. The irrigation infrastructure in the state mainly comprises of surface irrigation and ground water irrigation. About $72 \%$ of the requirement of irrigation is met through the tube wells dotting the Punjab landscape. As of 2009-2010, 13.15 lakh tube wells were operational in the state. The rest is met from surface water sources which mainly comprise of the $14500 \mathrm{~km}$ long canals and distributaries. There are three perennial rivers in the State - Ravi, Beas \& Sutlej and one no perennial river namely River Ghaggar. Besides several Choes, Nadies \& Khads also traverse the Sub mountainous \& alluvial plains before joining the parent river.

\subsection{Agriculture scenario in Punjab}

Punjab along with the neighboring state Haryana is referred as the "Grain Bowl of India". Agriculture is the major economic activity of the state, sustaining nearly $70-80 \%$ of the total population. Of the total geographical area, $84 \%$ is under agriculture use, $0.18 \%$ area is under cultivable wasteland and $8.94 \%$ area is not available for cultivation within the state. The cropping intensity in the state is averaged at $188 \%$, which is considered as one of the highest within the country. With only $1.6 \%$ of geographical area of the country, Punjab produces approximately, $22 \%$ of wheat, $10 \%$ of rice and $13 \%$ of cotton of the total production of these crops in the country. There are two major agricultural seasons in the state "Rabi" (winter crop) and "Kharif" (summer crop). The major crops grown during the Rabi season are wheat, arhar (Cajanus Cajan), barley (Hordeum vulgare), gram, mustard (Brassica juncea), sunflower (Helianthus annuus), cotton, dry chillies, sesamum and fodder, while during Kharif season paddy, bajra (Pennisetum glaucum), jowar (Sorghum bicolor), maize (Zea mays), moong (Vigna radiata), ground nut (Arachis hypogaea) and sugarcane (Saccharum arundinaceum) are important crops. Apart from these crops, there are various other crops such as vegetables, potatoes, tomatoes, green manure, etc., which are categorised as 'Insignificant Crops'. Here, it is important to mention that in the present study we categorized crops into four groups A1, A2, A3, and A4.

\subsection{Energy scenario in Punjab}

The installed capacity for power generation in Punjab was 4878 MW in 2010-11, and generated 27464.57 Million KWH of electricity. In addition, 28.5 MW of biomass power is being generated in the state;in 2010-11 also the installed capacity remained the same as in 2009-10. The highest consumer of electricity is the Industry (34.22\% of total electricity consumed in the state in $2009-10)$. All urban centers have $100 \%$ coverage and according to Census 2011, 95.5\% of the rural households in the state have direct electricity connection. The per capita electricity consumption $271 \mathrm{KWH}$ by Domestic sector, $81 \mathrm{KWH}$ by Commercial sector, $377 \mathrm{KWH}$ by the Industry, $27 \mathrm{KWH}$ by Public lighting and $346 \mathrm{KWH}$ by agriculture. The total per capita consumption being $1102 \mathrm{KWH}$ which is almost 1.5 times the national average $779 \mathrm{KWh}[7]$.

The Punjab State Electricity Board (PSEB) in 1967 started with a modest capacity of $62 \mathrm{MW}$, and has today a capacity of more than $6.0 \mathrm{GW}$, which serves about 5.9 million consumers and employs more than 0.08 million persons. The installed capacity at the end of the 10th five year plan is $6.088 \mathrm{GW}$ including own generation, share from Bhakra Beas Management Board (BBMB) and various central sector projects. During the 11th five year plan two thermal generation projects namely, LehraMohabat Stage-II (500 MW) and Goindwal Sahib Thermal Power Project (600 MW) are expected to be commissioned in the state. In addition to this, hydropower projects with capacity of $263 \mathrm{MW}$ are also expected to be commissioned during the 11th five year plan. Therefore, the total generation is expected to be about $7.451 \mathrm{GW}$ at the end of $11^{\text {th }}$ five year plan against the expected peak demand of $11.000 \mathrm{GW}$ during the year 2011-2012 with a deficit of $32 \%$ [8].

\section{Materials and Method}

The study consisted of intensive field surveys, group discussions with farmers and secondary data collection from all the 20 districts of the state from the agriculture sector. Field surveys based on to collect the residue sample from all the 20 districts of the state to evaluate the total crop residue generation in Punjab state the data also taken from Punjab Statistical Abstract 2010-2011. This data is categorized in four categories according to their uses and energy similarities. Table 2.1 shows different crop residues categories. 
Table 2.1 Various Crop Residue Types across Punjab

\begin{tabular}{|c|c|c|}
\hline Category & Residue Type & Crop \\
\hline \multirow[t]{4}{*}{$\mathrm{A} 1$} & \multirow[t]{4}{*}{ STRAW } & WHEAT \\
\hline & & PADDY \\
\hline & & PULSES \\
\hline & & BARLEY \\
\hline \multirow[t]{5}{*}{$\mathrm{A} 2$} & \multirow[t]{5}{*}{ STALKS } & COTTON \\
\hline & & MAIZE \\
\hline & & ARHAR \\
\hline & & MUSTARD \& RAPESEED \\
\hline & & SESAMUM \\
\hline \multirow[t]{2}{*}{ A3 } & BAGGASSE & SUGARCANE \\
\hline & TOPS \& LEAVES & SUGARCANE \\
\hline \multirow[t]{3}{*}{ A4 } & COBS & MAIZE \\
\hline & SHELLS & GROUNDNUT \\
\hline & HUSK & PADDY \\
\hline
\end{tabular}

\section{Results and Discussion}

\subsection{Crop residue generation in Punjab state}

The total residue generation from all crops in the state was reported to be 14462.85 Thousand Ton year ${ }^{1}$. Of this, Wheat and Paddy in the form of straw and husk alone contributed more than $86 \%$, while remaining was contributed by residues of cotton $(4.12 \%)$, fodder $(4.11 \%)$, sugarcane $(2.30 \%)$, etc. Sangrur, Fatehgarh Sahib, Rupnagar, S.B.S Nagar, Hoshiarpur, Ludhiana, Barnala and Moga reported as major crop residue potential districts within the state, which is due to the large agricultural land, maximum net sown area, higher crop yield, better irrigation facilities, more irrigated area, higher cropping intensity and introduction of high yielding varieties of crop seeds in these districts. Among least crop residues generation districts are Faridkot, Bathinda, S.A.S Nagar, Kapurthalla and Mansa. Table 3.1 shows the total crop residue generates among all 20 districts of Punjab state[8].

Table 3.1 Crop Residue Potential

\begin{tabular}{|c|c|c|c|c|c|c|c|c|}
\hline \multirow{2}{*}{$\begin{array}{l}\text { Sr. } \\
\text { No. }\end{array}$} & \multirow[t]{2}{*}{ District } & \multicolumn{4}{|c|}{ Crop Residue Potential in Thousand Ton } & \multirow{2}{*}{$\begin{array}{l}\text { Total } \\
\text { Unused } \\
\text { Crop } \\
\text { Residue } \\
\text { Produced in } \\
\text { Thousand } \\
\text { Ton }\end{array}$} & \multirow{2}{*}{$\begin{array}{l}\text { Area } \\
\text { cultivated }\end{array}$} & \multirow{2}{*}{$\begin{array}{l}\text { Reisdue } \\
\text { per unit } \\
\text { Area }\end{array}$} \\
\hline & & $\begin{array}{c}\text { Category } \\
\text { A1 }\end{array}$ & $\begin{array}{l}\text { Category } \\
\text { A2 }\end{array}$ & $\begin{array}{l}\text { Category } \\
\text { A3 }\end{array}$ & $\begin{array}{c}\text { Category } \\
\text { A4 }\end{array}$ & & & \\
\hline 1. & Gurdaspur & 745.05 & 42.79 & 15.66 & 117.95 & 921.45 & 704.1 & 1.30 \\
\hline 2. & Amritsar & 559.25 & 5.06 & 2.17 & 70.32 & 636.8 & 587 & 1.08 \\
\hline 3. & Tarn Taran & 564.74 & 6.46 & nil & 70.24 & 641.44 & 537.1 & 1.19 \\
\hline 4. & Kapurthala & 463.19 & 15.6 & 1.87 & 67.05 & 547.71 & 355 & 1.54 \\
\hline 5. & Jalandhar & 625.82 & 49.22 & 6.50 & 93.18 & 774.72 & 533.2 & 1.45 \\
\hline 6. & SBS Nagar & 252.49 & 79.16 & 3.36 & 50.99 & 386.00 & 230 & 1.67 \\
\hline 7. & Hoshiarpur & 359.88 & 330.42 & 9.46 & 120.69 & 820.45 & 467.5 & 1.75 \\
\hline 8. & Rupnagar & 166.8 & 104.82 & 1.15 & 35.99 & 308.76 & 194.2 & 1.58 \\
\hline 9. & SAS Nagar & 145.61 & 33.44 & 0.67 & 25.84 & 205.56 & 142.8 & 1.43 \\
\hline 10. & Ludhiana & 1166.01 & 13.78 & 1.46 & 158.48 & 1339.73 & 784.4 & 1.70 \\
\hline 11. & Firozpur & 1167.22 & 18.84 & 0.67 & 136.87 & 1323.6 & 1041 & 1.27 \\
\hline 12. & Faridkot & 437.19 & 1.92 & nil & 56.31 & 495.42 & 334.7 & 1.48 \\
\hline 13. & Muktsar & 533.78 & 11.92 & 0.67 & 59.48 & 605.85 & 508.7 & 1.19 \\
\hline 14. & Moga & 771.65 & 3.81 & nil & 102.58 & 878.04 & 526.3 & 1.66 \\
\hline 15. & Bathinda & 580.15 & 21.38 & nil & 60.18 & 669.33 & 618.9 & 1.08 \\
\hline 16. & Mansa & 414.19 & 13.32 & nil & 43.54 & 471.05 & 417.7 & 1.12 \\
\hline 17. & Sangrur & 1249.76 & 2.46 & 1.7 & 163.17 & 1417.09 & 849.3 & 1.66 \\
\hline 18. & Barnala & 485.88 & 2.17 & nil & 64.03 & 552.08 & 337.7 & 1.63 \\
\hline 19. & Patiala & 928.26 & 5.02 & 1.7 & 121.25 & 1056.23 & 713.6 & 1.48 \\
\hline 20. & Fatehgarh & 361.64 & 0.15 & 1.7 & 48.05 & 411.54 & 253.1 & 1.62 \\
\hline \multicolumn{6}{|c|}{ Total Crop Residue } & 14462.85 & 10136.3 & 28.88 \\
\hline
\end{tabular}




\subsection{Energy generation from crop residue}

In Punjab state 14462.85 Thousand Ton year $^{-1}$ crop residues generate from different crops. The agricultural residue consumption has been categorized into four categories such as domestic fuel, fodder, thatching and manuring in the state. The total residue consumption $71.04 \%$ of the total generation. Of this, domestic fuel and fodder together consume more than $68 \%$, while rest is used in thatching and manure form. Corresponding to the higher production potential, agricultural residue consumption is also reported high in districts Bhatinda, Ferozpur, Faridkot, Fatehgarh Sahib, Mansa and Muktsar. This is because of the large number of rural human and domestic cattle population. Most of the residue generated from wheat, barley and bajra is used for fodder, while Paddy husk besides being used as fodder, is also consumed in making dung cakes and sold within the neighbouring areas. While cotton and gram stalks are used as firewood at domestic level, major portion of mustard husk is traded or sold as fuel to the brick kiln owners by farmers. Table 3.2 shows the total estimated energy generation among all 20 districts of Punjab state.

Table 3.2 Energy potential from crop Residue

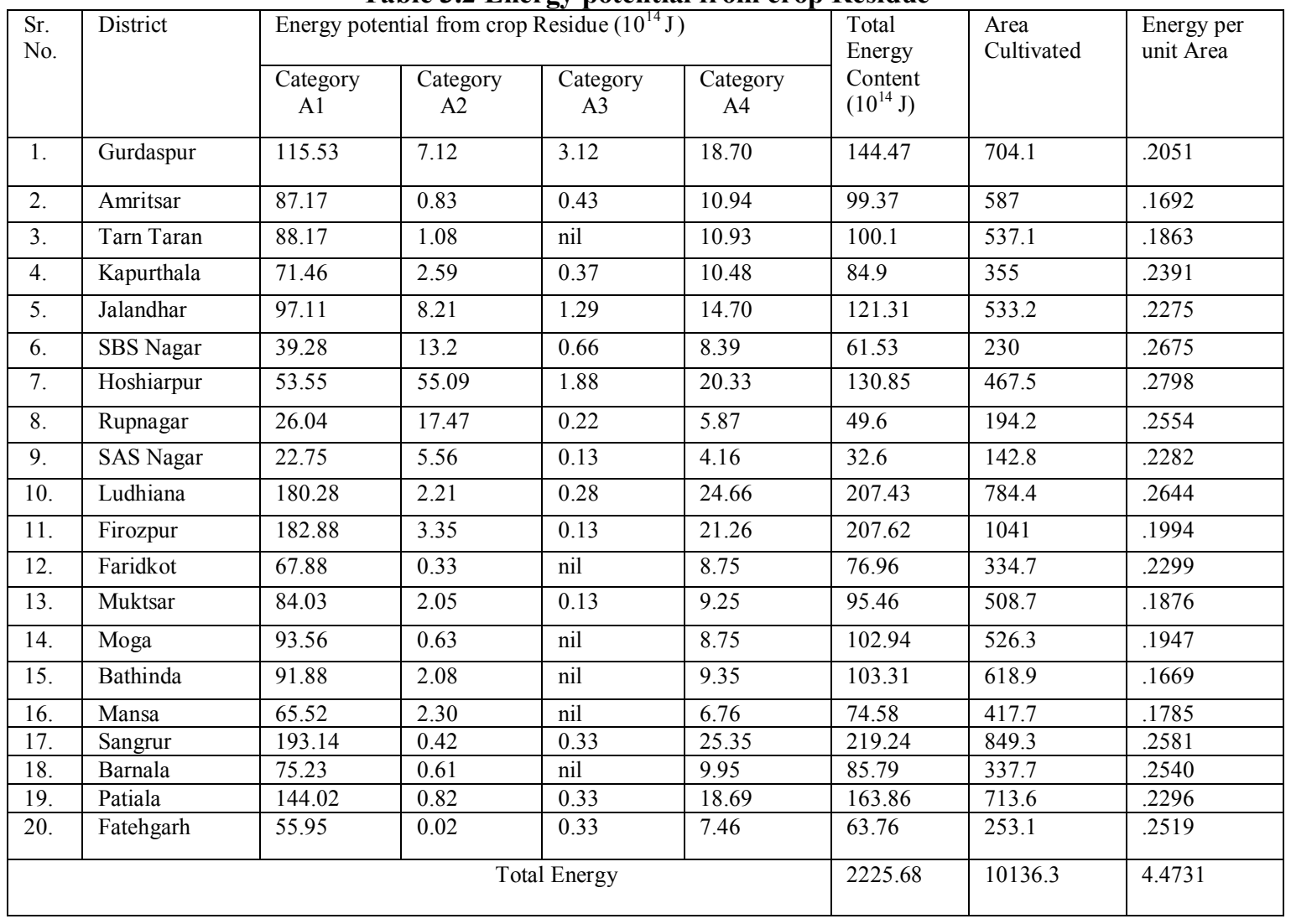

\subsection{Ultimate and Proximate analysis}

The various samples have been collected during field work and the following analysis has done in SSSNIRE, Kapurthala

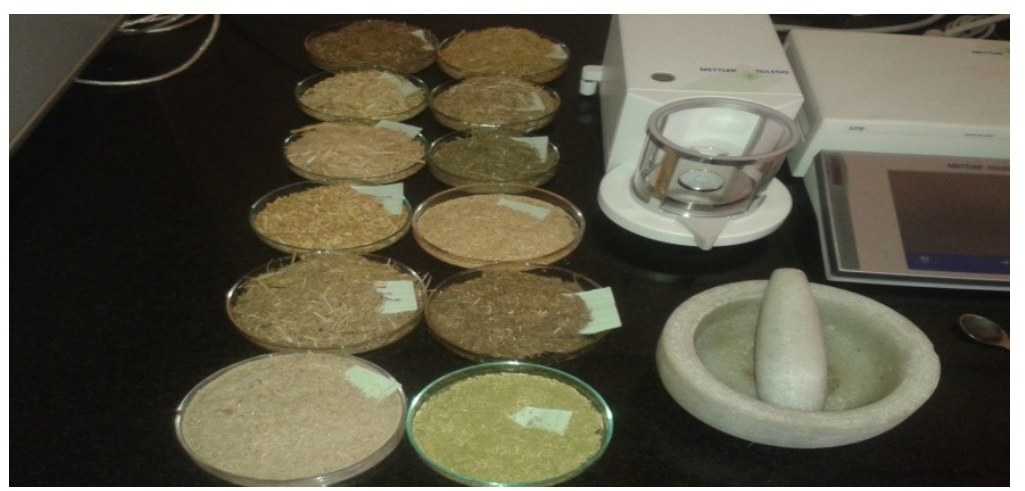

Fig. 3.1 Various Crop Residue Samples 
Table 3.3 Ultimate analysis of the samples

\begin{tabular}{|l|l|l|l|l|}
\hline Sample & Carbon \% & Hydrogen \% & Nitrogen \% & Sulphur \% \\
\hline Sugarcane Baggasse & 43.54 & 5.731 & 0.98 & 0.291 \\
\hline Paddy husk & 0.00 & 0.165 & 0.00 & 0.060 \\
\hline Arhar & 44.64 & 5.959 & 3.74 & 0.173 \\
\hline Seasum & 39.60 & 5.558 & 0.92 & 0.217 \\
\hline Wheat straw & 38.39 & 5.061 & 0.60 & 0.637 \\
\hline Maize stalk & 28.63 & 3.589 & 0.39 & 0.104 \\
\hline Cotton Stalk & 37.71 & 5.024 & 1.84 & 0.444 \\
\hline Mustard \& Rape seed & 39.56 & 5.516 & 1.54 & 0.409 \\
\hline Pulses & 40.23 & 5.645 & 2.11 & 0.207 \\
\hline $\begin{array}{l}\text { Sugarcane Tops \& } \\
\text { leaves }\end{array}$ & 40.80 & 5.418 & 0.64 & 0.252 \\
\hline Barley & 38.24 & 5.640 & 1.01 & 0.120 \\
\hline Paddy straw & 69.97 & 9.062 & 1.08 & 0.238 \\
\hline
\end{tabular}

Table 3.4 Proximate analysis of the samples

\begin{tabular}{|c|c|c|c|c|c|c|}
\hline $\begin{array}{l}\text { Sr. } \\
\text { No. }\end{array}$ & Sample name & $\begin{array}{l}\text { Moisture } \\
\text { Content }\end{array}$ & $\begin{array}{l}\text { Total weight } \\
\text { (crucible } \\
\text { sample) }\end{array}$ & $\begin{array}{l}\text { Wt. Of crucible } \\
\text { after exposing } \\
\text { sample to } 900 \\
\text { degree Celsius } \\
\text { for } 7 \text { minutes } \\
\text { (Volatile } \\
\text { Matter) }\end{array}$ & $\begin{array}{l}\text { Wt. Of crucible } \\
\text { after exposing } \\
\text { sample to } 550 \\
\text { degree Celsius } \\
\text { for } 2 \text { hours } \\
\text { *(content left } \\
\text { after } 900 \text { degree } \\
\text { exposure) (Ash } \\
\text { Content) }\end{array}$ & $\begin{array}{l}\text { LHV value } \\
(\mathrm{MJ} / \mathrm{Kg})\end{array}$ \\
\hline 1. & Sugarcane Baggase & 5 & $36.56 \mathrm{gm}$ & $34.19 \mathrm{gm}$ & $33.55 \mathrm{gm}$ & 20.0 \\
\hline 2. & Paddy husk & 6.6 & $33.04 \mathrm{gm}$ & $30.92 \mathrm{gm}$ & $33.55 \mathrm{gm}$ & 15.54 \\
\hline 3. & Arhar & 7.9 & $36.91 \mathrm{gm}$ & $34.75 \mathrm{gm}$ & $34.30 \mathrm{gm}$ & 18.58 \\
\hline 4. & Seasum & 7.3 & $39.28 \mathrm{gm}$ & $36.63 \mathrm{gm}$ & $36.03 \mathrm{gm}$ & 15.15 \\
\hline 5. & Wheat straw & 5.3 & $38.75 \mathrm{gm}$ & $37.09 \mathrm{gm}$ & $36.44 \mathrm{gm}$ & 17.15 \\
\hline 6. & Maize stalk & 6.1 & $34.18 \mathrm{gm}$ & $31.87 \mathrm{gm}$ & $31.48 \mathrm{gm}$ & 16.67 \\
\hline 7. & Cotton Stalk & 7.2 & $34.21 \mathrm{gm}$ & $31.90 \mathrm{gm}$ & $31.35 \mathrm{gm}$ & 17.40 \\
\hline 8. & Mustard \& Rape seed & 6.9 & $38.76 \mathrm{gm}$ & $36.45 \mathrm{gm}$ & $35.89 \mathrm{gm}$ & 17.00 \\
\hline 9. & Pulses & 6.1 & $36.91 \mathrm{gm}$ & $34.70 \mathrm{gm}$ & $34.17 \mathrm{gm}$ & 17.00 \\
\hline 10 . & $\begin{array}{l}\text { Sugarcane Tops \& } \\
\text { leaves }\end{array}$ & 6.6 & $33.04 \mathrm{gm}$ & $30.86 \mathrm{gm}$ & $30.26 \mathrm{gm}$ & 20.00 \\
\hline 11. & Barley & 6 & $39.27 \mathrm{gm}$ & $37.13 \mathrm{gm}$ & $36.52 \mathrm{gm}$ & 17.1 \\
\hline 12. & Paddy straw & 6.4 & $36.55 \mathrm{gm}$ & $34.56 \mathrm{gm}$ & $34.02 \mathrm{gm}$ & 15.03 \\
\hline
\end{tabular}

\subsection{Geographic Information Study}

The data of various crop residues have been collected from Punjab Statistical Abstract. As the availability this resource is spatially scattered, the supply of agricultural residue to power plants can be made secure by installing collection centers, where biomass is to be collected, compacted and stored for future use in the power plant. Optimizing the locations of power plants can reduce transportation cost. Spatial information technologies, particularly geographic information systems (GIS) can be highly helpful in evaluating the feasibility of setting up new biomass power plant in a given region. The collected data of crop residue potential and energy potential merged on Punjab map with the help of Punjab Remote Sensing Centre Ludhiana, Using Geographic Information System (GIS)[9]. 


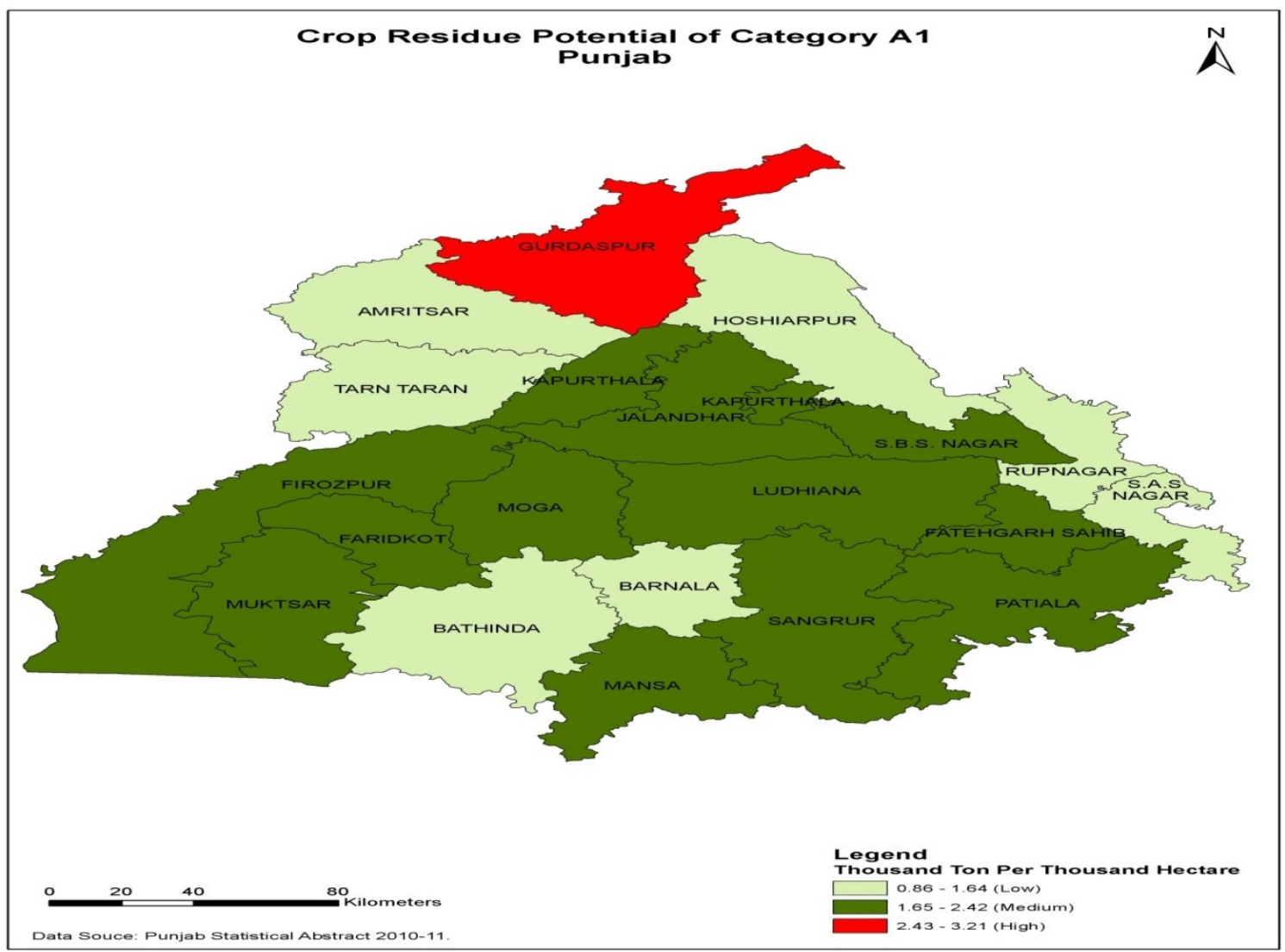

Fig 3.2 Crop Residue Potential of Category A1

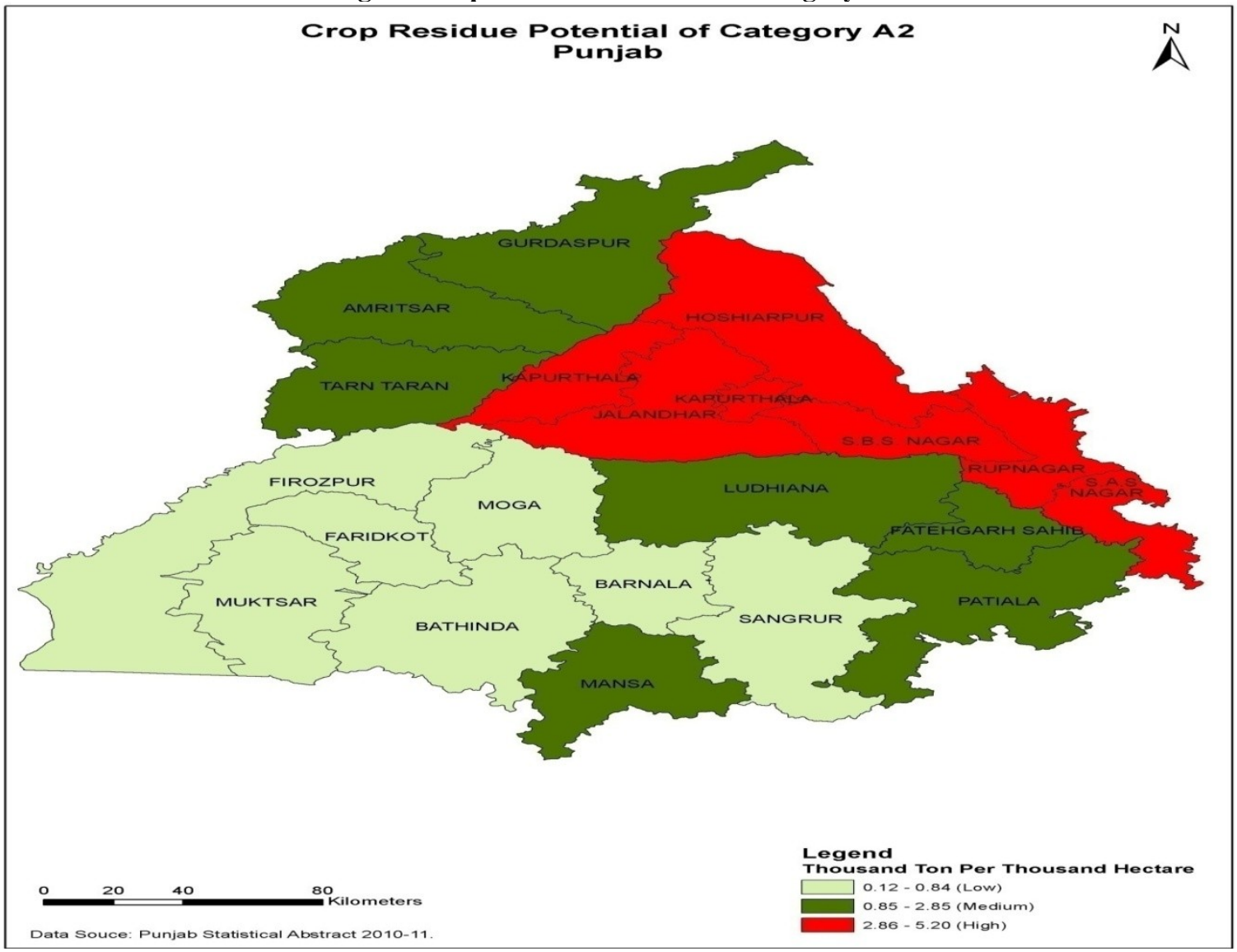

Fig 3.3 Crop Residue Potential of Category A2 


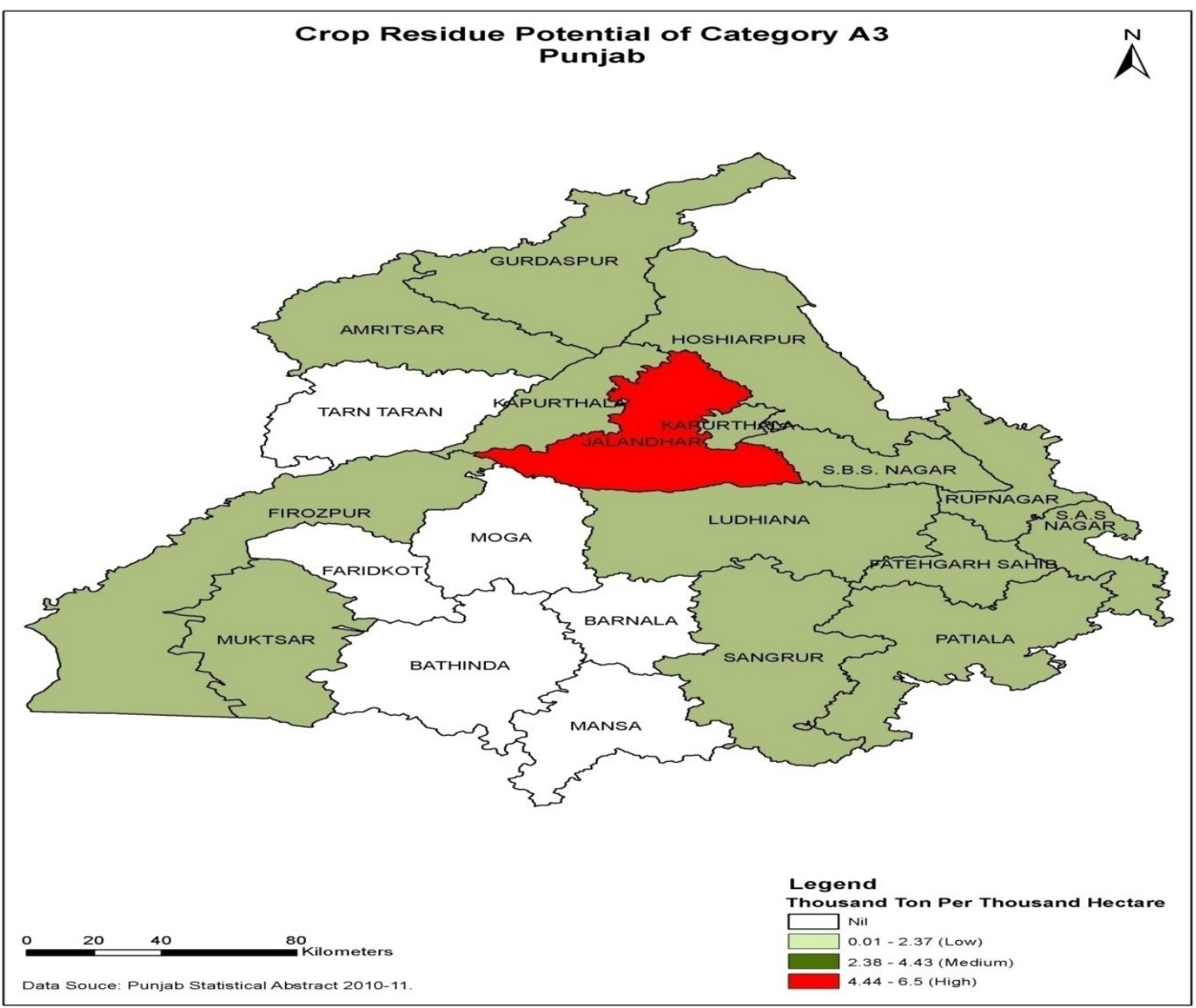

Fig. 3.4 Crop Residue Potential of Category A3

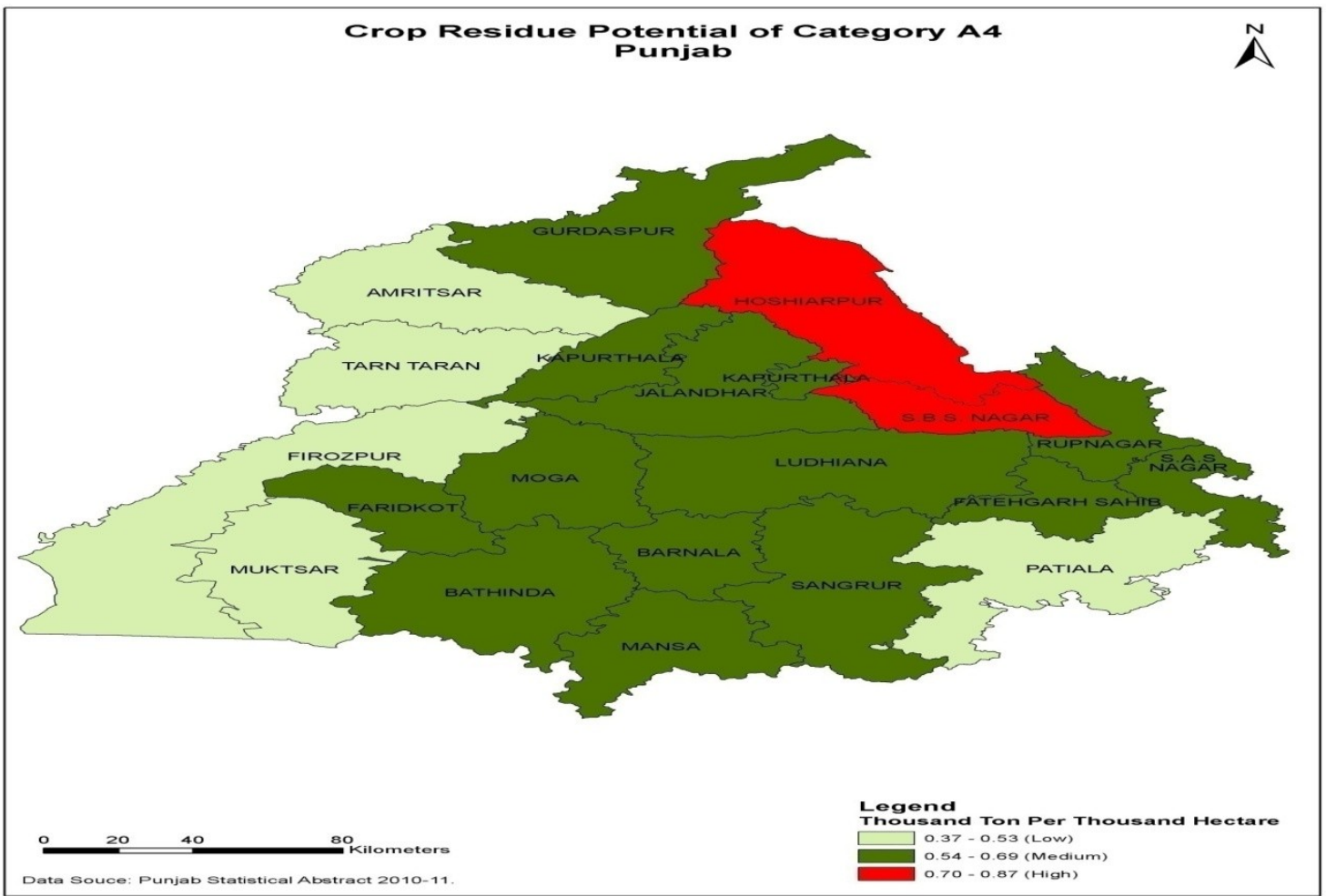

Fig. 3.5 Crop Residue Potential of Category A4 


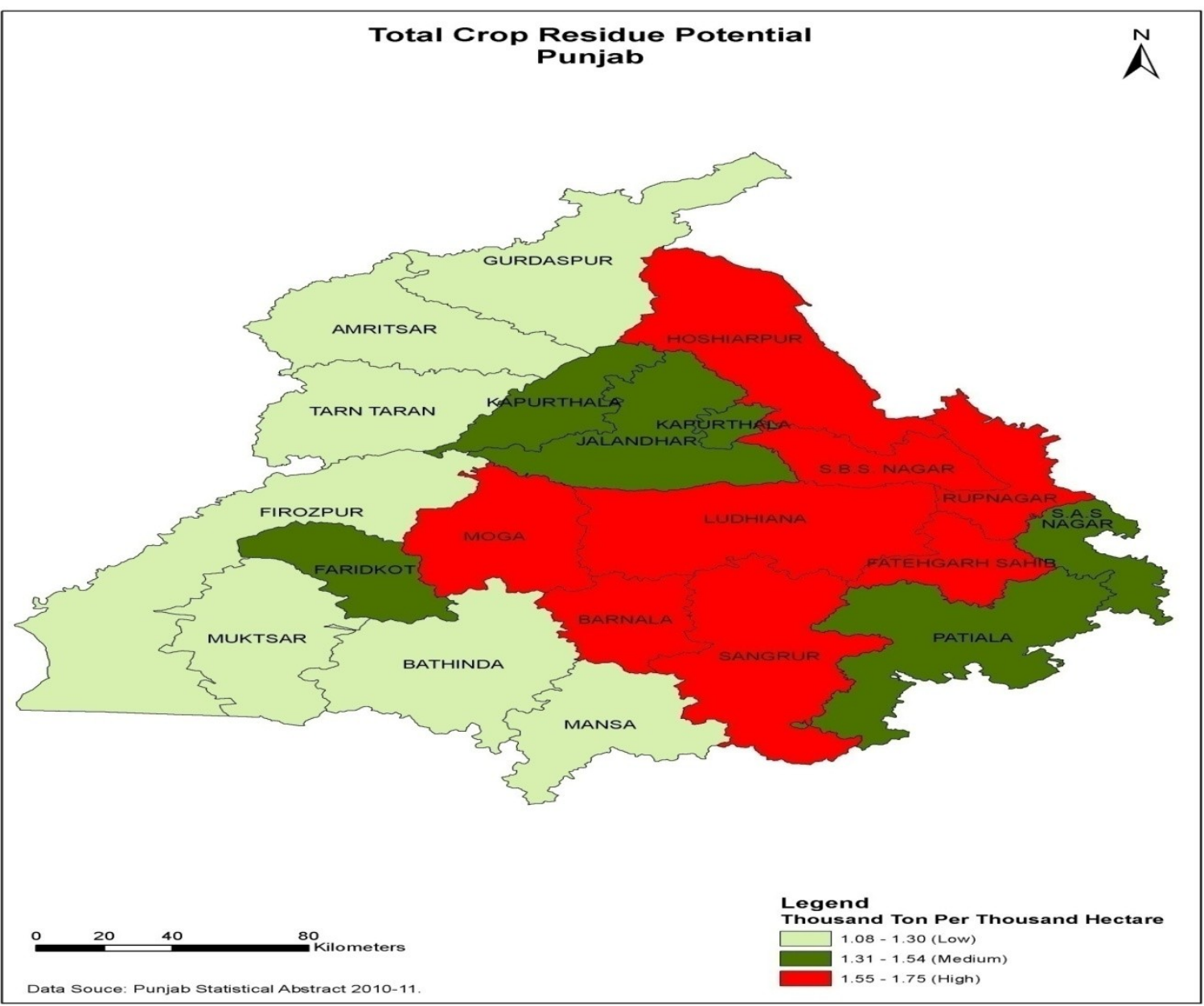

Fig. 3.6 Total Crop Residue Potential

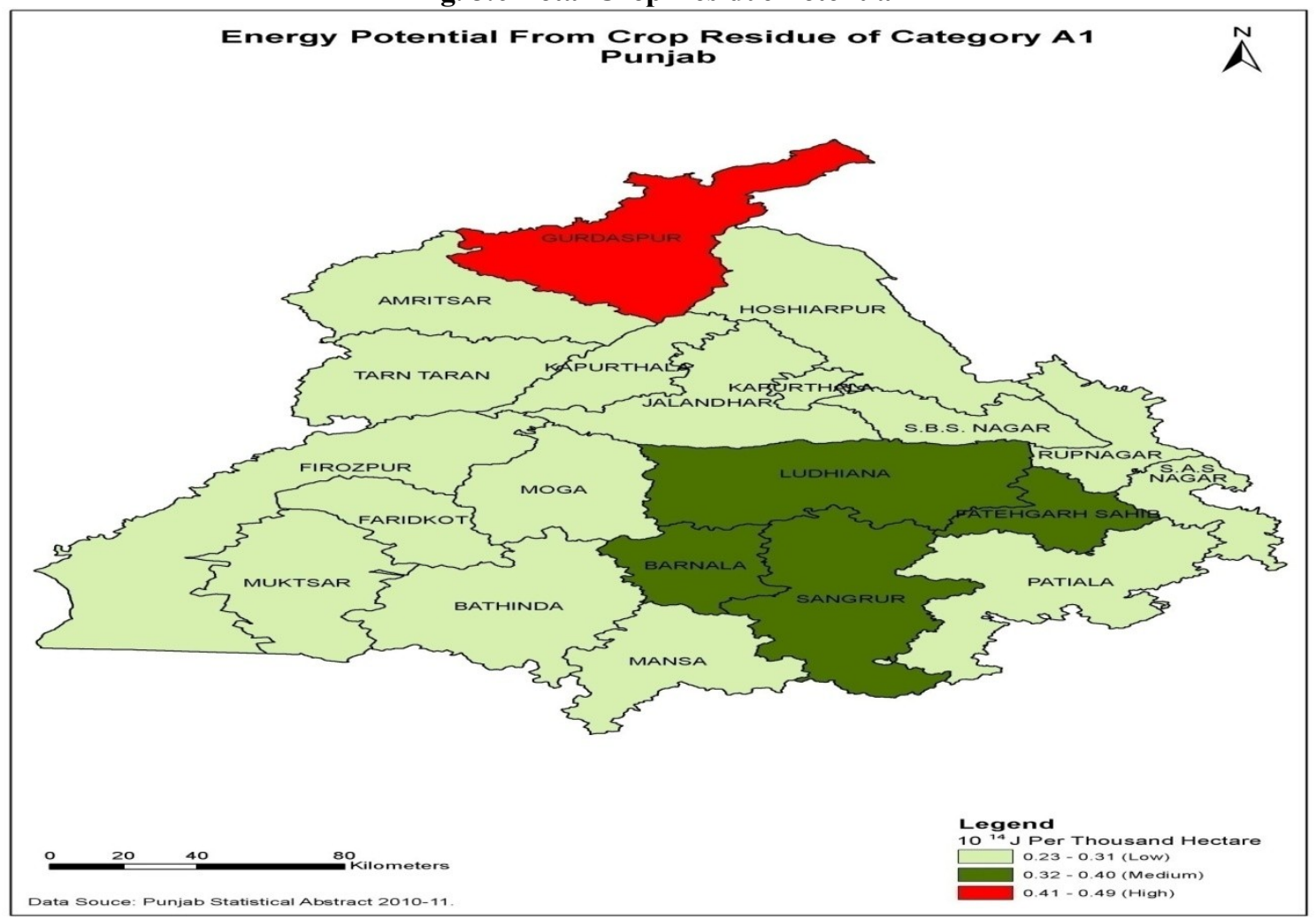

Fig. 3.7 Energy Potential of Category A1 


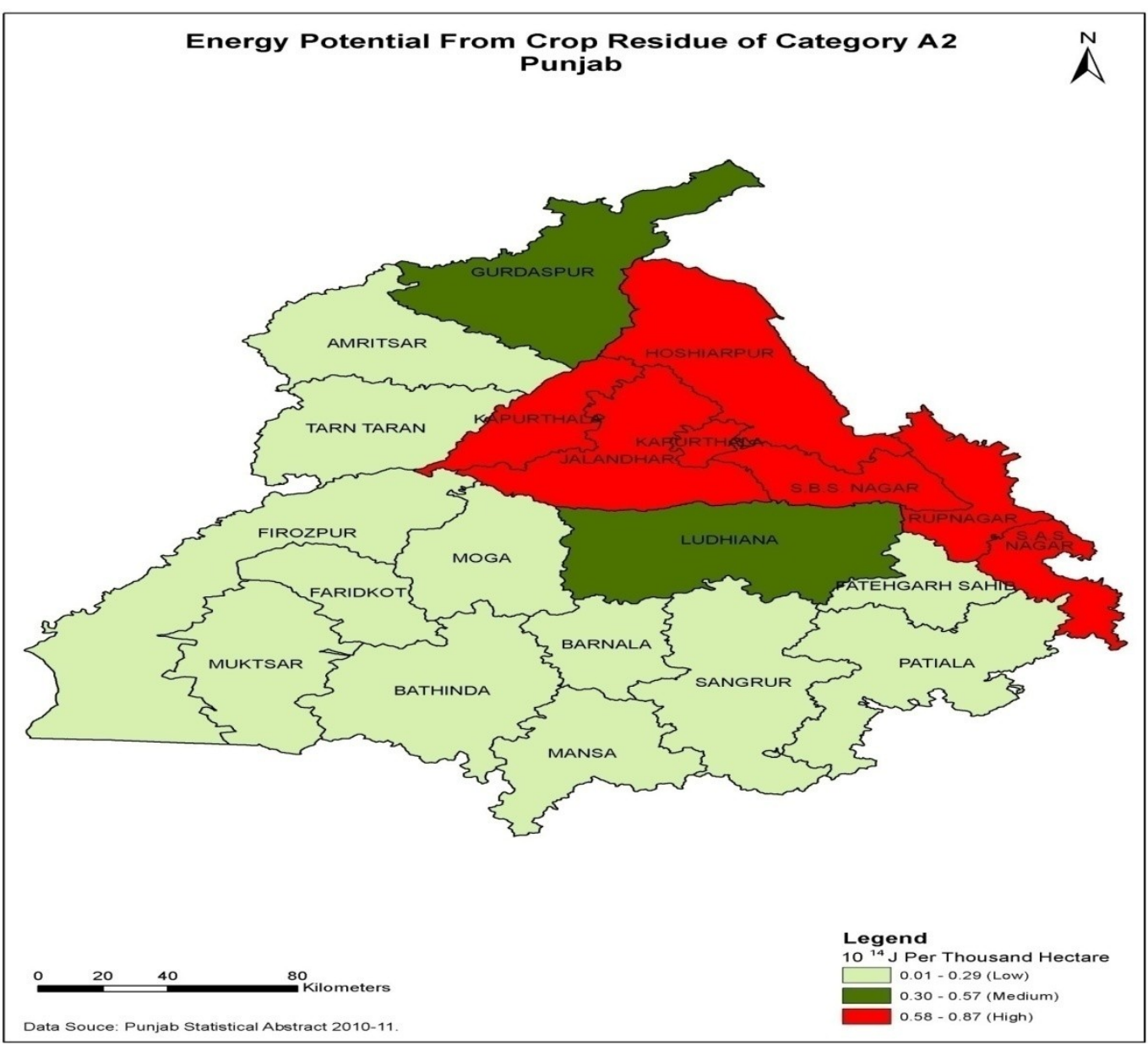

Fig. 3.8 Energy Potential of Category A2

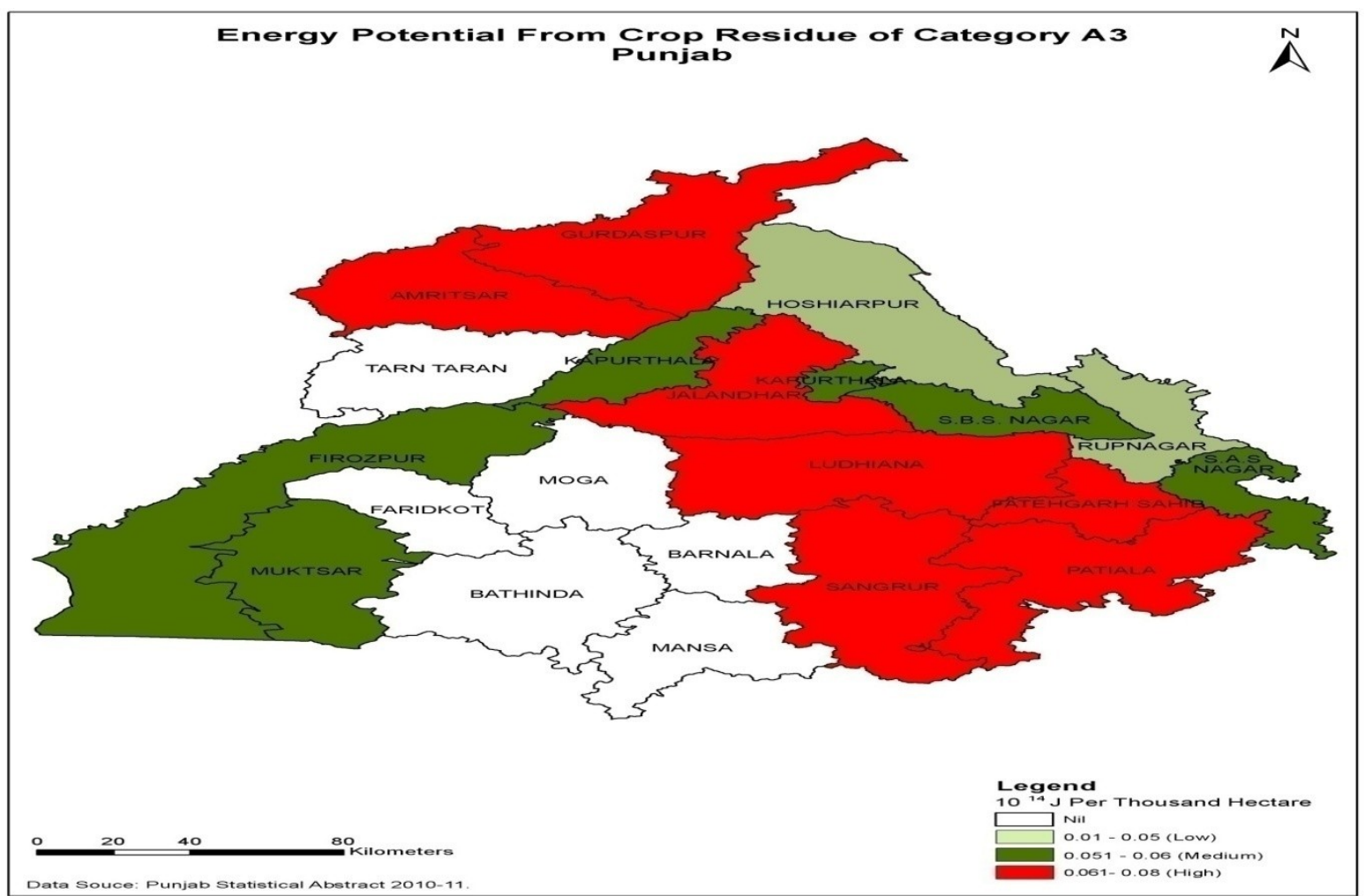

Fig. 3.9 Energy Potential of Category A3 


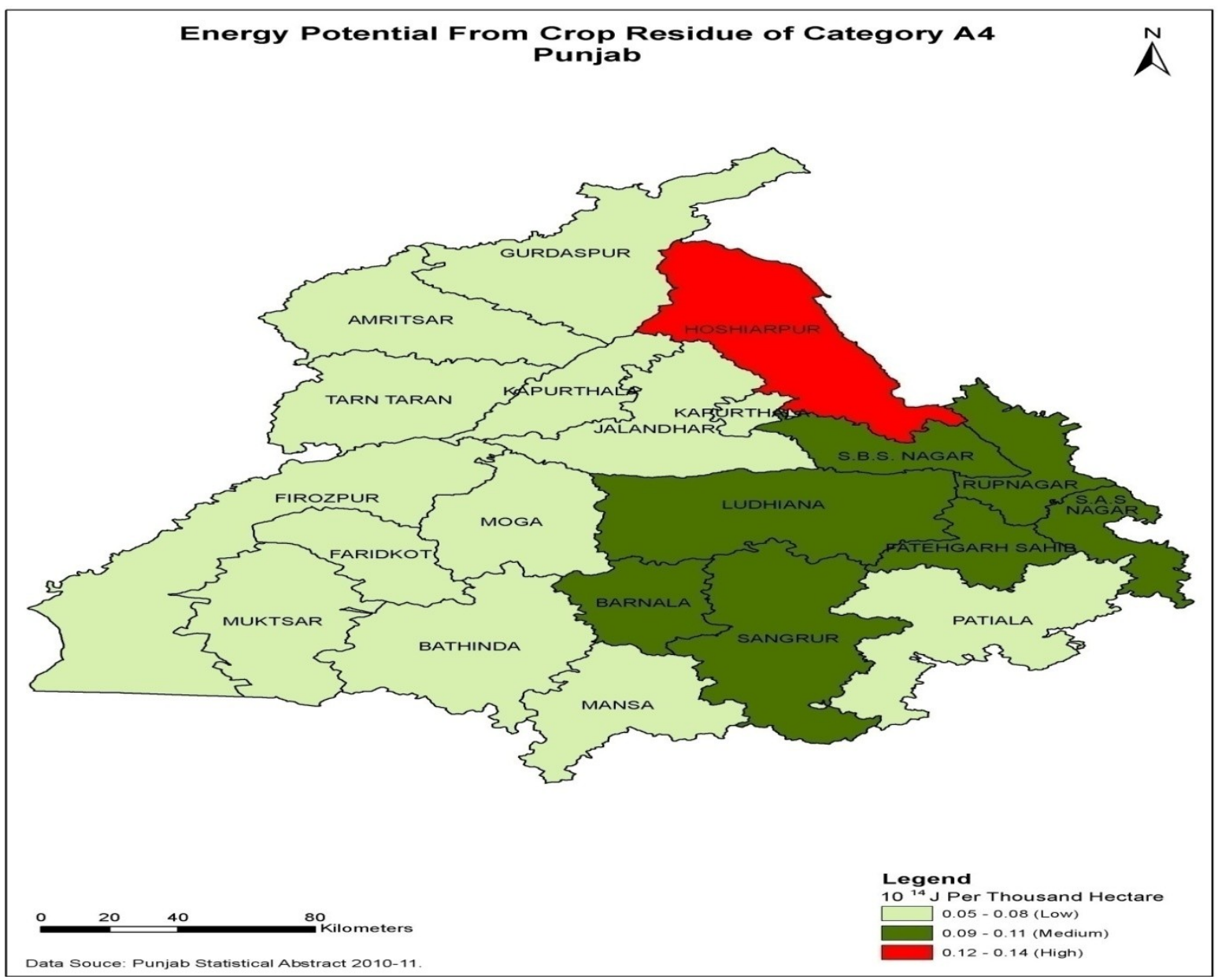

Fig. 3.10 Energy Potential of Category A4

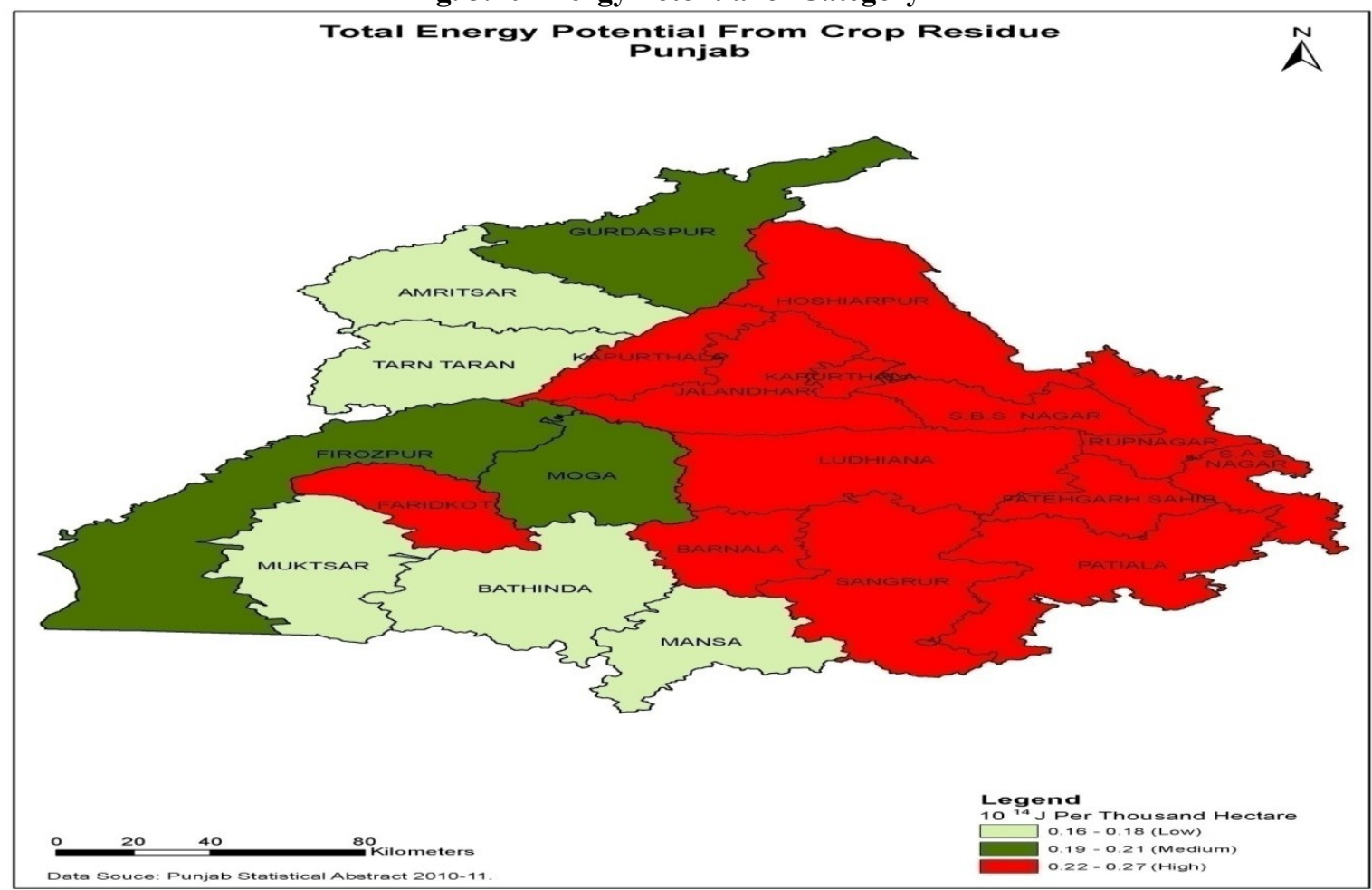

Fig. 3.11 Total Energy Potential 


\subsection{Gasification of Cotton Stalks}

Biomass gasification is an efficient and environmentally friendly way to produce energy. Gasification process is nothing but it is a conversion of solid fuel into gaseous fuel for wide applications. This whole process completed at elevated temperature range of $800-1300{ }^{\circ} \mathrm{C}$ with series of chemical reaction that is why it come under thermo chemical conversion. Biomass as a feedstock is more promising than coal for gasification due to its low sulphur content and less reactive character. The biomass fuels are suitable for the highly energy efficient power generation cycles based on gasification technology. It is also found suitable for cogeneration. The combustion in gasifier takes place in limited supply of oxygen it may be called partial combustion of solid fuel. The resulting gaseous product called producer gas is an energy rich mixture of combustible gas $\mathrm{H} 2, \mathrm{CO}, \mathrm{CH} 4$ and other impurities such as $\mathrm{CO} 2$, nitrogen, sulfur, alkali compounds and tars[10].

A schematic of Biomass Gasifier ( $5 \mathrm{~kW}$ ) is given in Fig 3.12 wherein the critical components have been identified. The biomass is fed through the feed door and is stored in the hopper. Limited and controlled amount of air for partial combustion entered through two air nozzles. The throat ensures relatively clean and good quality gas production. The grate holds charcoal for reduction of partial combustion products while allowing the ash to drop off in the ash collection cone. The gas outlet is connected with the engine via venturi scrubber, separator box cum fine filter and check filter with an air control valve to facilitate running of the engine in dual mode.

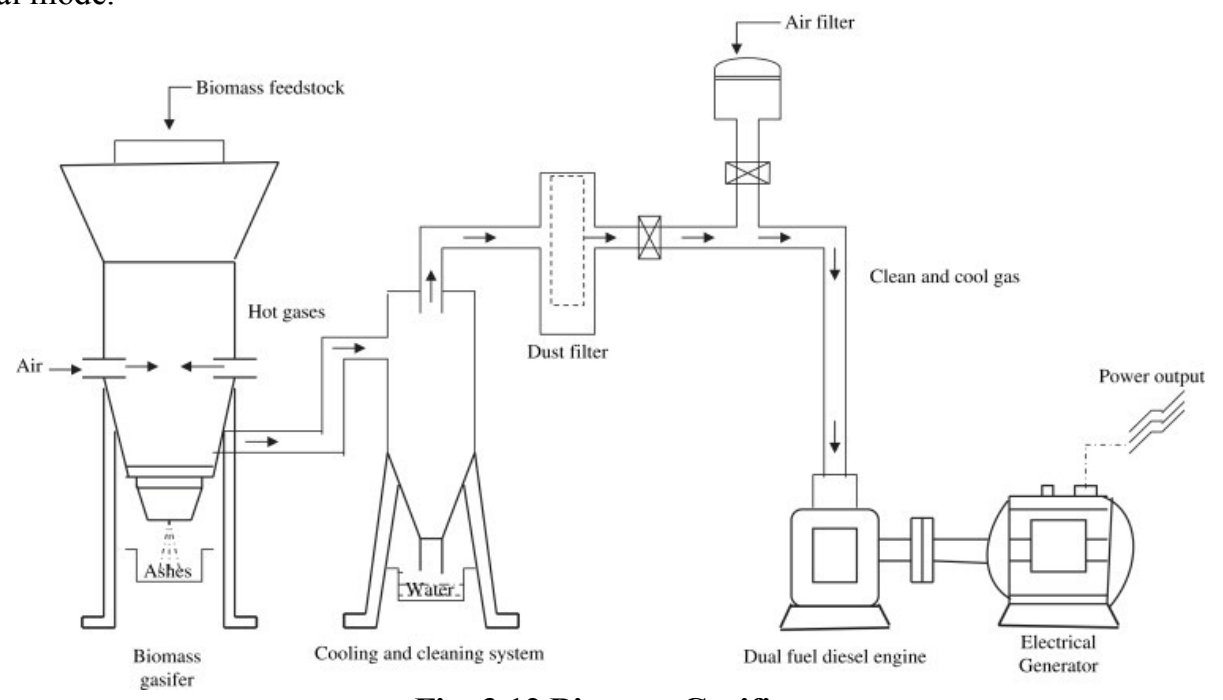

Fig. 3.12 Biomass Gasifier

The various diesel consumption observations from the experiment conducted on gasifier engine set with cotton stalk biomass sample used are listed below:

Table 3.5 Consumption of diesel at Different Load in Diesel mode of Engine

\begin{tabular}{|l|c|c|c|}
\hline Load (KW) & Time (sec) & Diesel Consumption (ml) & $\begin{array}{c}\text { Specific diesel } \\
\text { Consumption (ml/sec) }\end{array}$ \\
\hline 0.5 & 18.11 & 4 & 0.2208 \\
\hline 1.5 & 14.39 & 4 & 0.2779 \\
\hline 2.0 & 10.49 & 4 & 0.3813 \\
\hline 2.5 & 9.12 & 4 & 0.4385 \\
\hline 3.0 & 7.64 & 4 & 0.5235 \\
\hline
\end{tabular}

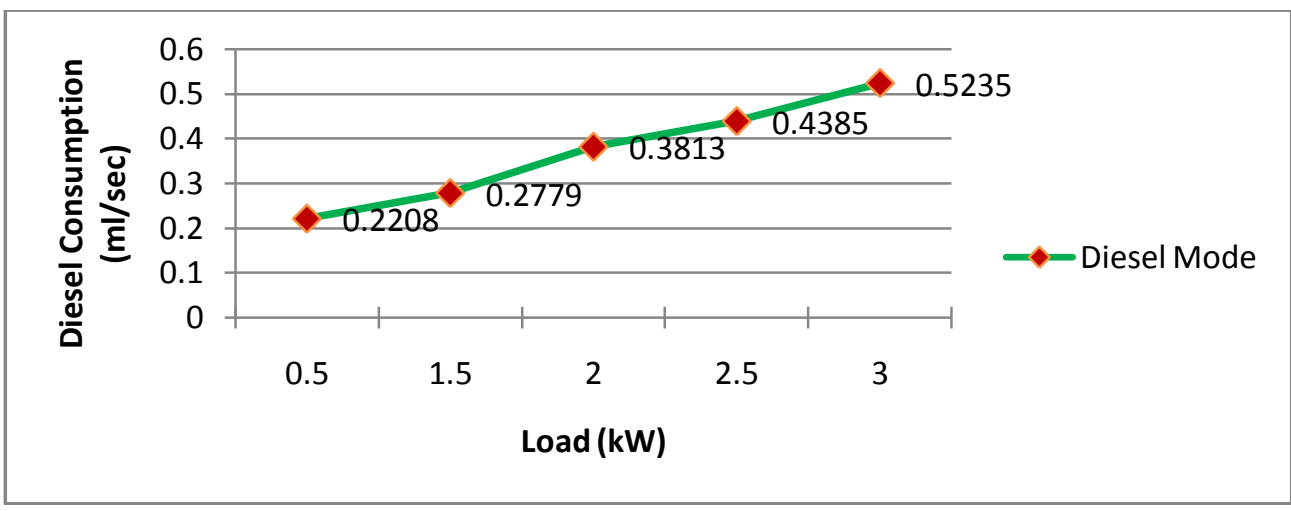

Fig. 3.13 Diesel Consumption v/s Load in Diesel Mode of Engine 
Table 3.6 Consumption of Diesel at Different Load in Dual mode of Engine (Cotton Stalks)

\begin{tabular}{|l|c|c|c|}
\hline Load (KW) & Time (sec) & $\begin{array}{c}\text { Diesel Consumption } \\
(\mathrm{ml})\end{array}$ & $\begin{array}{l}\text { Specific diesel } \\
\text { Consumption (ml/sec) }\end{array}$ \\
\hline 0.5 & 17.34 & 1 & 0.0576 \\
\hline 1.5 & 13.82 & 1 & 0.0723 \\
\hline 2.0 & 12.78 & 1 & 0.0782 \\
\hline 2.5 & 10.35 & 1 & 0.0966 \\
\hline 3.0 & 9.40 & 1 & 0.1063 \\
\hline
\end{tabular}

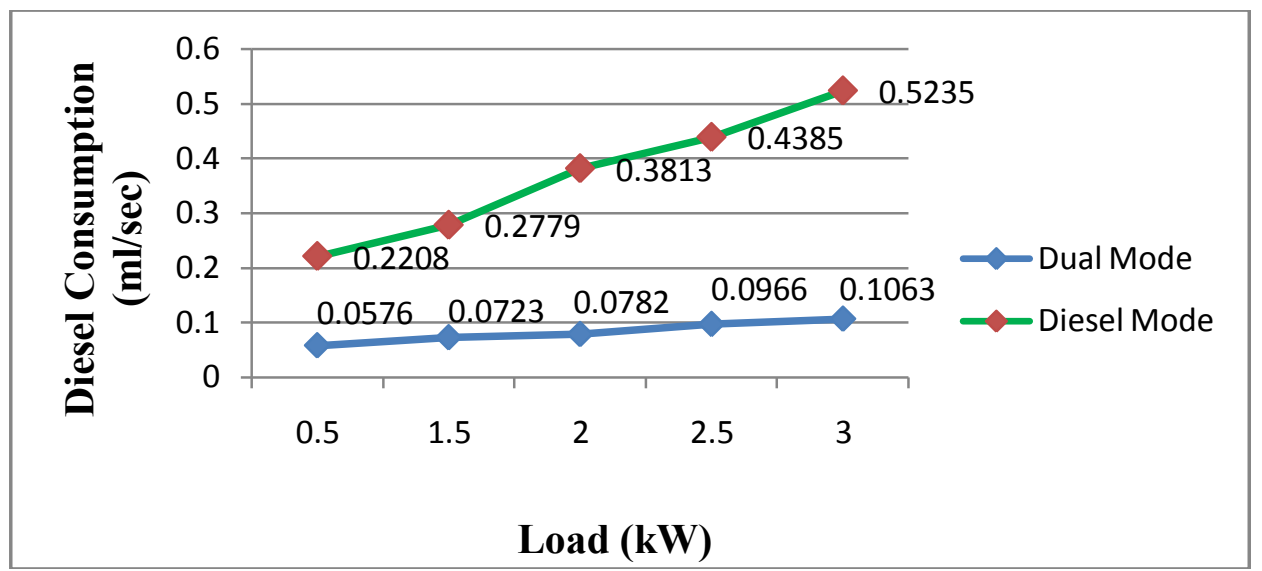

Fig. 3.14 Diesel Consumption v/s Load Dual Mode of Engine (Cotton Stalk)

Table 3.7 Percentage (\%) of Diesel saving

\begin{tabular}{|c|c|c|l|}
\hline Load (KW) & $\begin{array}{l}\text { Specific diesel Consumption } \\
(\mathrm{ml} / \mathrm{sec}) \text { in single mode }\end{array}$ & $\begin{array}{l}\text { Specific diesel Consumption } \\
(\mathrm{ml} / \mathrm{sec}) \text { in dual mode }\end{array}$ & Percentage (\%) of Diesel saving \\
\hline 0.5 & 0.2208 & 0.0576 & 73.91 \\
\hline 1.5 & 0.2779 & 0.0723 & 73.98 \\
\hline 2.0 & 0.3813 & 0.0782 & 79.49 \\
\hline 2.5 & 0.4385 & 0.0966 & 77.97 \\
\hline 3.0 & 0.5235 & 0.1063 & 79.69 \\
\hline
\end{tabular}

\section{Conclusion}

By comparing the properties of coal and crop residue we found that the properties of coal are resemble with crop residue properties and hence the coal is replaceable with crop residue.

Fig. 3.2 with refers to data of Table no. 3.1 crop residue potential for category A1 for state of Punjab has been given in Fig. 3.2. Districts Bathinda, Barnala, Tarn taran, Amritsar, Hoshiarpur, Rupnagar and S.A.S Nagar has low productivity of category A1 in the range of 0.86-1.64 Thousand Ton per Thousand hectare. Districts Firozpur, Faridkot, Shri Muktsar Sahib, Moga, Jalandhar, Kapurthala, Ludhiana, Mansa, Sangrur, Patiala, SBS Nagar and Fatehgarh Sahib have medium productivity of category A1 in the range of 1.65-2.42 Thousand Ton per Thousand hectares. District Gurdaspur high productivity of category A1 in the range of 2.433.21 Thousand Ton per Thousand hectares.

Fig. 3.3 with refers to data of Table no. 3.1 crop residue potential for category A2 for state of Punjab has been given in Fig. 3.3. Districts Bathinda, Firozpur, Faridkot, Shri Muktsar Sahib, Moga, Sangrur and Barnala have low productivity of category A2 in the range of 0.12-0.84 Thousand Ton per Thousand hectares. Districts Ludhiana, Mansa, Patiala,Fatehgarh Sahib, Tarn taran, Amritsar and Gurdaspur have medium productivity of category A2 in the range of 0.85-2.85 Thousand Ton per Thousand hectares. Districts Hoshiarpur, Jalandhar, Kapurthala, Rupnagar, S.A.S Nagar and SBS Nagar high productivity of category A2 in the range of 2.86-5.20 Thousand Ton per Thousand hectares.

Fig. 3.4 with refers to data of Table no. 3.1 crop residue potential for category A3 for state of Punjab has been given in Fig. 3.4. Districts, Firozpur, Shri Muktsar Sahib, Sangrur, Ludhiana, Patiala, Fatehgarh Sahib, Amritsar, Gurdaspur, Hoshiarpur, Jalandhar, Kapurthala, Rupnagar, S.A.S Nagar and SBS Nagar have low productivity of category A2 in the range of 0.01-2.37 Thousand Ton per Thousand hectares. Districts Jalandhar have high productivity of category A3 in the range of 4.44-6.5 Thousand Ton per Thousand hectares. Districts Bathinda, Mansa, Barnala, Faridkot, Moga and Tarn Taran have nill productivity of category A3.

Fig. 3.5 with refers to data of Table no. 3.1 crop residue potential for category A4 for state of Punjab has been given in Fig. 3.5 Districts Shri Muktsar Sahib, Patiala, Firozpur, Tarn taran and Amritsar has low productivity of category A4 in the range of $0.37-0.53$ Thousand Ton per Thousand hectares. Districts Rupnagar, S.A.S Nagar, Faridkot, Shri Muktsar Sahib, Moga, Jalandhar, Bathinda, Barnala, Kapurthala, Ludhiana, Mansa, 
Sangrur, Patiala and Fatehgarh Sahib have medium productivity of category A4 in the range of 0.54-0.69 Thousand Ton per Thousand hectares. District Hoshiarpur and SBS Nagar high productivity of category A4 in the range of 0.70-0.87 Thousand Ton per Thousand hectares.

Fig. 3.6 with refers to data of Table no. 3.1 crop residue potential for total crop residue for state of Punjab has been given in Fig. 3.6 Districts Shri Muktsar Sahib, Firozpur, Tarn taran, Bathinda, Mansa, Gurdaspur and Amritsar has low productivity of total crop residue in the range of 1.08-1.30 Thousand Ton per Thousand hectares. Districts S.A.S Nagar, Faridkot, Patiala, Jalandhar and Kapurthala have medium productivity of total crop residue in the range of 1.31-1.54 Thousand Ton per Thousand hectares. District Hoshiarpur, Rupnagar, Moga, Fatehgarh Sahib, Ludhiana, Sangrur, Barnala and SBS Nagar high productivity of total crop residue in the range of 1.55-1.75 Thousand Ton per Thousand hectares.

V. $\quad$ Fig. 3.7 with refers to data of Table no. 3.2 energy potential from crop residue for category A1 for state of Punjab has been given in Fig. 3.7 Districts Shri Muktsar Sahib, Firozpur, Tarn taran, Bathinda, Mansa, S.A.S Nagar, Faridkot, Patiala, SBS Nagar, Jalandhar, Hoshiarpur, Rupnagar, Moga, Kapurthala and Amritsar has low productivity of category A1 in the range of 0.23-0.31 Thousand Ton per Thousand hectares. Districts Fatehgarh Sahib, Ludhiana, Sangrur and Barnala have medium productivity of category A1 in the range of $0.32-0.40$ Thousand Ton per Thousand hectares. District Gurdaspur has high productivity of category A1 in the range of 0.41-0.49 Thousand Ton per Thousand hectares.

Fig. 3.8 with refers to data of Table no. 3.2 energy potential from crop residue for category A2 for state of Punjab has been given in Fig. 3.8 Districts Shri Muktsar Sahib, Firozpur, Tarn taran, Bathinda, Mansa, Faridkot, Patiala, Moga, Fatehgarh Sahib, Sangrur, Barnala and Amritsar has low productivity of category A2 in the range of 0.01-0.29 Thousand Ton per Thousand hectares. Districts Hoshiarpur, Kapurthala, SBS Nagar, Jalandhar, Rupnagar and S.A.S Nagar have medium productivity of category A2 in the range of 0.30-0.57 Thousand Ton per Thousand hectares. District Gurdaspur and Ludhiana have high productivity of category A2 in the range of $0.58-0.87$ Thousand Ton per Thousand hectares.

Fig. 3.9 with refers to data of Table no. 3.2 energy potential from crop residue for category A3 for state of Punjab has been given in Fig. 3.9 Districts Hoshiarpur and Rupnagar have low productivity of category A3 in the range of 0.01-0.05 Thousand Ton per Thousand hectares. Districts Kapurthala, Shri Muktsar Sahib, Firozpur, SBS Nagar and S.A.S Nagar have medium productivity of category A3 in the range of 0.051-0.06 Thousand Ton per Thousand hectares. Districts Jalandhar, Gurdaspur, Patiala, Fatehgarh Sahib, Sangrur, Amritsar and Ludhiana have high productivity of category A3 in the range of 0.061-0.08 Thousand Ton per Thousand hectares. Districts Tarn taran, Bathinda, Mansa, Faridkot, Moga and Barnala have nill productivity of category A3.

Fig. 3.10 with refers to data of Table no. 3.2 energy potential from crop residue for category A4 for state of Punjab has been given in Fig. 3.10 Districts Shri Muktsar Sahib, Firozpur, Tarn taran, Bathinda, Mansa, Gurdaspur, Faridkot, Patiala, Jalandhar, Moga, Kapurthala and Amritsar have low productivity of category A4 in the range of 0.05-0.08 Thousand Ton per Thousand hectares. Districts Fatehgarh Sahib, Ludhiana, S.A.S Nagar, SBS Nagar, Rupnagar, Sangrur and Barnala have medium productivity of category A4 in the range of 0.09-0.11 Thousand Ton per Thousand hectares. District Hoshiarpur has high productivity of category A1 in the range of 0.12-0.14 Thousand Ton per Thousand hectares.

Fig. 3.11 with refers to data of Table no. 3.2 total energy potential from crop residue for state of Punjab has been given in Fig. 3.11 Districts Shri Muktsar Sahib, Tarn taran, Bathinda, Mansa and Amritsar have low productivity of total energy potential in the range of 0.16-0.18 Thousand Ton per Thousand hectares. Districts Firozpur, Gurdaspur and Moga have medium productivity of total energy potential in the range of 0.19-0.21 Thousand Ton per Thousand hectares. Districts Hoshiarpur, Rupnagar, S.A.S Nagar, Faridkot, Patiala, Jalandhar, Kapurthala, Fatehgarh Sahib, Ludhiana, Sangrur, Barnala and SBS Nagar high productivity of total energy potential in the range of $0.22-0.27$ Thousand Ton per Thousand hectares. respectively.

Total crop residue potential and energy potential is 14462.85 Thousand ton and $2225.68 \times 10^{14} \mathrm{~J}$

As the overall efficiency in the biomass crop residue conversion process is very low in the range of $13 \%$. It can be further increased by proper management of crop residue resources at all the level.

From Fig 3.2 to Fig 3.11 it has been found that the biomass waste power plant can be installed throughout the Punjab state.

From Table no. 3.5 and Fig no. 3.13 shows that the consumption of diesel at different loads in diesel mode engine and it is found that as the load on the engine increase from $0.5 \mathrm{KW}$ to $3 \mathrm{KW}$ the specific diesel consumption in $\mathrm{ml} / \mathrm{sec}$ also increases.

From Table no. 3.6 and Fig no. 3.14 shows that the consumption of diesel decreases in dual fuel mode (Producer gas has been produced using cotton stalks). It is further investigated that as the load increase from 0.5 $\mathrm{KW}$ to $3 \mathrm{KW}$ on the engine the specific diesel consumption also increases. 
From Table no. 3.7 it is found experimentally that by using cotton stalk as crop residue in Dual fuel coupled engine there is approximate $80 \%$ of diesel saving, when the engine is work at full load $3 \mathrm{KW}$.

\section{References}

[1]. Rai SN, Chakrabarti SK, "Demand and supply of fuelwood, timber and fodder in India. Dehradun: Forest Survey of India" Government of India; (1996). p. 35.

[2]. Shukla PR., "Wood energy and global climate change-FAO/ RWEDP" Wood Energy News 11 (1996) 112-118.

[3]. Das S, Jash T., "District-level biomass resource assessment: a case study of an Indian state West Bengal" Biomass Bioenergy 33 (2009) 137-143.

[4]. Sinha CS, Ramana PV, Joshi V, "Designing effective intervention strategies" Energy Pol 22 (1994) 190-198.

[5]. http://peda.gov.in/eng/ENERGY CONSERVETION/index.html

[6]. psest.gov.in/en/pdfs/climatechange/09-Chapter.

[7]. pscst.gov.in/en/pdfs/climatechange/02-Chapter

[8]. Chauhan S., "District wise agriculture biomass resource assessment for power generation: A case study from an Indian state, Punjab" International Journal of Biomass and Bioenergy 37 (2012) 205-212.

[9]. Singh J., Panesar B.S., Sharma S.K., "Geographical distribution of agricultural residues and optimum sites of biomass based power plant in Bathinda, Punjab" International Journal of Biomass and Bioenergy 35(2011)4455-4460.

[10]. PanwarN.L., Kothari R., Tyagi V.V., "Thermo chemical conversion of biomass - Eco friendly energy routes" International Journal of Renewable and Sustainable Energy Reviews 16 (2012) 1801- 1816 